\title{
FATORES QUE INFLUENCIARAM ALUNOS INGRESSANTES NA ESCOLA DE ENFERMAGEM DA USP, EM 1981, NA ESCOLHA DA ENFERMAGEM COMO OPÇÃO PROFISSIONAL
}

\author{
Edna Apparecida Moura Arcuri* \\ Thelma Leite de Araújo** \\ Maria Amélia Campos Oliveira***
}

ARCURI, E. A. M.; ARAÜJO, T. L. de; OLIVEIRA, M. A. C. Fatores que influenciaram alunos ingressantes na Escola de Enfermagem da USP, em 1981, na escotha da enfermagem como opção profissional. Rev. Esc. Enf. USP, São Paulo, $17(1): 5-19,1983$.

$O$ esfudo objetivou caracterizar alguns aspectos sócio-econômicos da população ingressante na Escola de Enfermagem da Universidade de São Paulo e verificar quais as opcões destes alunos nas diversas vezes em que fizeram exame vestibular. A população estudada foi de 51 alunos que cursavam a disciplina Introdução à Enfermagem. $O$ instrumento foi um questionário, onde foram abordados itens relacionados aos motivos que influenciaram a escolha da enfermagem como opsão profissional. Concluiu-se que a maioria dos alunos $\dot{e}$ do sexo feminino, de 18 a 20 anos, procedente da Capital e Grande Sáo Paulo, proveniente de familias de variadas faixas econômicas da população; $47 \%$ dos alunos apontaram enfermagem como a profissão que gostariam de exercer, embora tivessem prestado vestibulares para outras carreiras, preferencialmente medicina. Mais de $60 \%$ dos alunos pretendem realizar nova tentativa em exame vestibular. Os motivos mais citados que influenciaram a escolha profissional destes alunos foram: interesse pelas ciências biológicas, desejo de ajudar pessoas e preocupação com o nivel de saúde da população.

\section{INTRODUÇÃO}

$\mathrm{Na}$ estrutura curricular do Curso de Graduação da Escola de Enfermagem da Universidade de São Paulo (EEUSP), a disciplina onde o aluno começa a ter contato especificamente com a profissão é Introdução à Enfermagem, oferecida no segundo semestre do primeiro ano, quando os alunos ainda estão cursando as disciplinas da parte préprofissional; é pré-requisito para Fundamentos de Enfermagem, ofere-

* Enfermeira. Mestre em Enfermagem. Professor Assistente do Departamento de Enfermagem Médico-Cirúrgica da Escola de Enfermagem da USP. - discíplina Introdução e Fundamentos de Enfermagem.

** Enfermeira. Auxiliar de Ensino do Departamento de Enfermagem Médico-Cirúrgica da Escola de Enfermagem da USP. - disciplina Introdução e Fundamentos de Enfermagem.

*** Enfermeira. Auxiliar de Ensino do Departamento de Enfermagem Médico-Cirúrgica da Escola de Enfermagem da USP. - disciplina Introdução e Fundamentos de Enfermagem, na ocasião da elaboração do trabalho. 
cida no terceiro semestre, sob a responsabilidade do mesmo grupo de docentes.

Nos últimos anos, os docentes que participam no ensino destas disciplinas têm-se preocupado em introduzir, logo no início das aulas, técnicas de dinâmica de grupo, que possibilitem conhecimento melhor entre alunos e docentes. A abordagem, embora sistematizada, tem tido caráter informal, baseada principalmente na formação de sub-grupos de reconhecimento social, com alunos e docentes "na berlinda" o que oportuniza o conhecimento mais individualizado dos elementos do grupo.

Nas avaliações dessas sessões de dinâmica de grupos os alunos sempre consideravam oportuna a utilização de técnicas que possibilitassem o melhor conhecimento dos colegas; disseram que muitas vezes desconheciam a existência de elementos casados, chefes ou mães de família entre eles. Alguns achavam mesmo que as reuniões com esta finalidade deveriam ser realizadas no início do Curso de Graduação.

O objetivo da dinâmica de grupo, portanto, era promover melhor entrosamento entre os elementos componentes de cada classe; entretanto a apresentação geral dos alunos que cursavam a disciplina em 1981, chamou atenção a ênfase dada por eles ao problema da opção profissional, condicionada ao número de pontos exigidos na primeira fase do vestibular, da indefinição profissional, além de outras referências ou manifestações de comportamento que sugeriram um alto índice de ansiedade no grupo.

Por exemplo, foram vários os alunos que assim se apresentaram: "Sou Fulana de Tal, tenho ... anos, prestei vestibular para ......... tantas vezes, resolvi optar pela enfermagem porque teria maior chance de ingressar, mas vou continuar tentando .....". Já outros alunos admitiam que começavam a gostar do curso, mas talvez só no ano seguinte poderiam se definir melhor.

$E$ do conhecimento de todos, como lembrou ARCURI ${ }^{1}$ por ocasião de aula inaugural da EEUSP/1982, que o atual sistema educacional no que diz respeito ao ingresso no curso superior, assim como o maior número de profissões em oferta, são causas de situações conflitantes para muitos jovens, no momento em que precisam fazer uma opção profissional nos exames vestibulares.

Neste ano, 1982, 132.258 alunos disputaram 8.028 vagas na Universidade de São Paulo (USP), dado este que confirma a grande dificuldade de ingresso nessa instituição. A relação entre o número de vagas e o número de inscrições faz com que o número de pontos a ser alcançado seja muito elevado, o que conduz à desistência prévia e mudança para outras profissões de menor interesse ao aluno. Sabe-se que na área biológica, a desistência é geralmente referente aos cursos de medicina e odontologia, profissões que atraem grande número de candidatos que entretanto, desistem previamente devido o elevado número de pontos a 
ser atingido na primeira fase dos exames vestibulares, quando cerca de $80 \%$ dos candidatos são eliminados.

Em algumas escolas do segundo grau a definição da área (biológica, exata ou humana) é feita no início do primeiro ano quando os alunos só têm catorze ou quinze anos de idade, fator este, também responsável pela dúvida quanto a escolha da profissão, dúvida esta que persiste durante todo o curso colegial e muitas vezes até os primeiros anos do curso superior.

MORRIS \& RUSSO $^{5}$ preocupados com a elevada taxa de abandono do curso de enfermagem e considerando que o sucesso e satisfação profissional na escola e na prática poderiam estar relacionados com os motivos iniciais para a escolha da profissão, elaboraram um estudo resultante de um consenso entre enfermeiros e estudantes entrevistados sobre a alta taxa de atrito, problemas de inadaptação na prática e dificuldades apresentadas pelos estudantes, sobretudo durante a primeira fase do trabalho de campo, quando cursam as disciplinas iniciantes.

Na EEUSP, o número de estudantes que abandonaram o curso nos últimos anos foi: 1975, 11 alunos; 1976, 15; 1977, 21; 1978, 14; 1979, 21; 1980, 12; e 1981, 12 alunos. Como pode ser visto, em 1977 e 1979 o número de desistência ultrapassou $25,0 \%$ do número de alunos ingressantes (80), abandono considerado muito alto, principalmente por se tratar de escola gratuita. Nos demais anos a desistência tem estado em torno de 15,0 a $17,0 \%$.

Embora o depoimento dos alunos em 1981 não causasse surpresa aos docentes, pensou-se que grande carga emocional por parte de alguns deles deveria merecer atenção especial. A tentativa de um conhecimento individual mais profundo, tornou-se relevante. Embora o currículo atual não seja centrado no aluno, como propõe BARBOSA ${ }^{2}$, é de consenso dos docentes considerar e respeitar ao máximo a individualidade do estudante, na proposta de assumir com seriedade o difícil papel de educador na formação de homens pensantes e profissionais capazes.

Assim, na tentativa de melhor conhecer os alunos e colher dados a serem utilizados na disciplina subseqüente, Fundamentos de Enfermagem, período tremendamente marcante na vida do estudante, elaborou-se um questionário com os seguintes objetivos:

1 - Conhecer as escolhas que cada aluno fez em exames vestibulares, anteriores ou concomitantes.

2 - Verificar o número de alunos que pretendem prestar novos vestibulares e as possiveis razões.

3 - Conhecer as razões que levaram os alunos a optarem pela enfermagem, utilizando o modelo MORRIS \& RUSSO ${ }^{5}$, adaptado à realidade da EEUSP, segundo vivência dos autores. 


\section{METODOLOGIA}

A população estudada foi composta de 51 alunos que cursavam a disciplina de Introdução à Enfermagem, presentes em sala de aula na data em que foi aplicado o instrumento.

Após ter sido explicado a importância dos dados a serem obtidos, o questionário (Anexo) foi distribuído e respondido individualmente pelos alunos, em período aproximado de trinta a quarenta minutos. As nove questões iniciais do questionário foram importantes para o melhor conhecimento do grupo, mas não apresentam interesse específico para este trabalho, razão porque não será apresentada a tabulação ou discussão dos resultados nesta publicação.

Duas autoras deste trabalho permaneceram na sala com o intuito de esclarecer dúvidas, já que se optou por não testar o instrumento anteriormente, a fim de evitar a comunicação entre os alunos sobre o conteúdo do mesmo. Esta conduta foi tomada baseada na vivência dos docentes quanto à expectativa, ansiedade e às vezes influência de alguns alunos sobre os outros, neste período do curso.

\section{RESULTADOS}

TABELA 1 - Número e frequiência dos alunos ingressantes na EEESP em 1981 que se sentiam seguros para fazer opção profissional ao final do segundo grau.

\begin{tabular}{lcc}
\hline \multirow{2}{*}{ SEGURANGA } & \multicolumn{2}{c}{ ALUNOS } \\
\cline { 2 - 3 } & $\mathrm{N}$ & $\%$ \\
\hline Sim & 17 & 33,3 \\
Não & 34 & 66,7 \\
\hline TOTAL & 51 & 100,0 \\
\hline
\end{tabular}

TABELA 2 - Atitude familiar em relação a opção profissional dos alunos ingressantes na EEUSP em 1981.

\begin{tabular}{lcr}
\hline & & \multicolumn{2}{c}{ ALUNOS } \\
\cline { 2 - 3 } ATITUDE & Ne & $\%$ \\
\hline Aceitação & 35 & 68,7 \\
Indiferença & 08 & $\mathbf{1 5 , 7}$ \\
Rejeição & 04 & 7,8 \\
Não responderam & 04 & $\mathbf{7 , 8}$ \\
\hline TOTAL & 51 & 100,0 \\
\hline
\end{tabular}


TABELA 3 - Experiências anteriores em exames vestibulares dos alunos ingressantes na EEUSP em 1981.

\begin{tabular}{|c|c|c|}
\hline \multirow{2}{*}{ EXPERIENCIAS } & \multicolumn{2}{|c|}{ ALUNOS } \\
\hline & $\mathbf{N}$ & $\%$ \\
\hline Em 3 profissões & 09 & 17,6 \\
\hline Im 2 profissões & 11 & 21,6 \\
\hline Em 1 profissăo & 18 & 35,3 \\
\hline Nåo fizeram outros exames vestibulares & 13 & 25,5 \\
\hline TOTAL & 51 & 100,0 \\
\hline
\end{tabular}

TABELA 4 - Profissões citadas pelos alunos ingressantes nas tentativas anteriores a 1981.

\begin{tabular}{|c|c|c|c|c|}
\hline \multirow{2}{*}{ PROFISSOES } & \multicolumn{2}{|c|}{ ALUNOS } & \multicolumn{2}{|c|}{ TENTATIVAS } \\
\hline & $\mathbf{N}$ & $\%$ & $N^{9}$ & $\%$ \\
\hline Medicina & 21 & 31,3 & 102 & 69,3 \\
\hline Enfermagem & 19 & 28,3 & 27 & 18,3 \\
\hline Odontologia & 04 & 6,0 & 04 & 2,7 \\
\hline Terapia Ocupacional & 04 & 6,0 & 05 & 3,4 \\
\hline Psicologia & 02 & 3,0 & 02 & 1,4 \\
\hline Fonoaudiologia & 02 & 3,0 & 02 & 1,4 \\
\hline Engenharia & 02 & 3,0 & 02 & 1,4 \\
\hline Matemática & 01 & 1,5 & 02 & 1,4 \\
\hline Outros & 12 & 17,9 & 01 & 0,7 \\
\hline TOTAL & 67 & 100,0 & 147 & 100,0 \\
\hline
\end{tabular}

TABELA 5 - Profissões que os alunos ingressantes na EEUSP em 1981 escolheriam, em ordem de prioridade.

\begin{tabular}{|c|c|c|c|c|c|c|}
\hline \multirow{3}{*}{ PROFISSOES } & \multicolumn{6}{|c|}{ PRIORIDADES } \\
\hline & \multicolumn{2}{|c|}{14} & \multicolumn{2}{|c|}{$2^{4}$} & \multicolumn{2}{|c|}{ 3* } \\
\hline & $\mathbf{N}^{\circ}$ & $\% *$ & No & $\%:$ & $\mathbf{N e}$ & $\% *$ \\
\hline Enfermagem & 24 & 47,0 & 11 & 21,6 & 0 & - \\
\hline Medicina & 11 & 21,6 & 6 & 11,8 & 1 & 2,0 \\
\hline Odontologia & 3 & $\mathbf{5 , 9}$ & 1 & 2,0 & 0 & - \\
\hline Fonoaudiologia & 0 & - & $\mathbf{0}$ & - & 5 & 10,0 \\
\hline Terapia Ocupacional & 1 & 2,0 & 4 & 7,8 & 0 & - \\
\hline Educação FYsica & 2 & 4,0 & 2 & 4,0 & 3 & $\mathbf{5 , 9}$ \\
\hline
\end{tabular}

* A porcentagem fol calculada sobre o total de 51 alunos, embora, alguns alunos não tenham indicado nenhuma profissão nas tres prioridades e outros apenas em uma ou duas delas. 
TABELA 6 - Fatores que influenciaram os alunos ingressantes na EEUSP em 1981, na escolha da Enfermagem, segundo notas atribuídas de 0 a 3 , com base no modelo de MORRIS \& RUSSO ${ }^{5}$.

\begin{tabular}{|c|c|c|}
\hline \multirow[t]{2}{*}{ FATORES } & PONTOS & ATRRBUWOS \\
\hline & No & $\%$ \\
\hline Interesse pelas ciências biológicas & 121 & $\mathbf{7 9 , 0}$ \\
\hline Desejo de ajudar pessoas & 106 & $\mathbf{7 0 , 0}$ \\
\hline Preocupação com o nível de saúde da população & 72 & $\mathbf{4 7 , 0}$ \\
\hline Desenvolvimento da personalidade com o objetivo & & \\
\hline de compreender melhor as pessoas & 64 & 42,0 \\
\hline Incentivo da familia & 58 & 38,0 \\
\hline Interesse financeiro & $\mathbf{5 3}$ & 34,6 \\
\hline Experiência de trabalho hospitalar ou comunitário & 44 & 28,7 \\
\hline Fxperiência anterior em hospitais como & & \\
\hline pacientes (pessoal ou familiar) & 44 & 28,7 \\
\hline Ingresso mais fácil na área biológica & 36 & 23,5 \\
\hline «Status» profissional & 26 & 17,0 \\
\hline Enfermeiras na família & 26 & 17,0 \\
\hline
\end{tabular}

A porcentagem total $(100,0 \%)$ refere-se ao valor 153 , que representa o valor máximo que seria obtido se todos os alunos atribuissem a nota máxima a cada fator.

\section{DISCUSSÃO}

A discussão dos dados de identificação dos alunos ingressantes, conforme o comentário feito na metodologia do estudo, não apresenta interesse à esta publicação, uma vez que sua utilização estava direcionada à possibilidade de aplicação imediata dos resultados, ou seja, o melhor conhecimento dos alunos que cursariam a disciplina Fundamentos de Enfermagem. É preciso destacar, porém que foram de grande valia ao planejamento e avaliação dos dados de identificação, os estudos de NAKAMAE ${ }^{\circ}$ e MANZOLLI \& MONJELEONE ${ }^{4}$, autores que vêm estudando o perfil do estudante de enfermagem.

Apenas para breve elucidação do leitor, 51 alunos $(63,7 \%)$ responderam ao questionário por estarem presentes em sala de aula no dia em que o mesmo foi aplicado. Desses alunos, $40(78,4 \%)$ encontravam-se na faixa etária de 18 a 20 anos, $10(19,6 \%)$ na faixa de 21 a 23 anos e apenas $1(2,0 \%)$ acima de 23 anos. Constatou-se que 1 aluno $(2,0 \%)$ era casado e só 1 aluno $(2,0 \%)$ do sexo masculino. Com relação à procedência, $36(70,5 \%)$ procedem da Capital e Grande São Paulo; de famílias pertencentes a variadas faixas econômicas da população; $13(25,5 \%)$ famílias recebem de 0 a 5 salários-minimos e $40(78,4 \%)$ delas possuindo de dois a quatro filhos.

Dos 51 alunos, $8(15,7 \%)$ trabalham, mas somente $1(2,0 \%)$ afirmou ser economicamente independente, e outro $(2,0 \%)$ depende do seu trabalho e do marido. 
Os demais comentários desta discussão referem-se às perguntas de número 10 a 20 do questionário aplicado.

Indagados se ao término do segundo grau, os alunos haviam sentido segurança para fazer uma opção profissional (tabela 1), apenas 17 alunos $(33,3 \%)$ responderam afirmativamente, $34(66,7 \%)$ sentiam-se indecisos, com dúvidas entre várias profissões da mesma área, talvez por imaturidade cronológica ou psicológica e por falta de informações precisas sobre as profissōes. Muitos informaram estar seguros apenas quanto à área de preferência e não quanto à profissão.

A porcentagem de famílias que rejeitaram $(7,8 \%)$ a enfermagem como profissão foi pequena, (tabela 2) se comparada à aceitação $(68,7 \%)$. Sabe-se entretanto que, enquanto a indiferença por parte de algumas famílias parece não ser prejudicial ao desenvolvimento do aluno, a rejeição interfere de forma preponderante. Muitos alunos com grande potencial, mas que apresentaram bloqueios nas primeiras experiências hospitalares, reclamaram em entrevistas que os pais não concordavam com a sua escolha do curso de enfermagem. Observou-se também que, dentre os casais, pais dos alunos entrevistados, a resistência maior localizava-se na figura do pai.

Foi ansiosamente esperado o resultado das respostas sobre as experiências anteriores em exames vestibulares (tabela 3 ), as profissões citadas nas experiências anteriores em exames vestibulares (tabela 4) e as profissões que os alunos ingressantes na EEUSP em 1981 escolheriam dentro de três prioridades (tabela 5). E preciso lembrar que até 1981 era possivel indicar mais de uma opção profissional por ocasião da matrícula aos exames vestibulares, o que não ocorre atualmente, quando a opção é referente a três escolas que oferecem o mesmo curso. Este fato, entretanto, não deve suscitar dúvidas no leitor, pois a questão número 13 visou conhecer a real vontade do aluno quanto à escolha $\mathrm{e}$ não à possibilidade de escolha. Em contrapartida a abertura opcional referente à profissão foi provavelmente a causa de 9 alunos $(17,6 \%)$ terem tido experiências anteriores em exames vinculados a três profissões diferentes e $11(21,6 \%)$ em duas profissões (tabela 3$)$.

Quanto a vontade condicionada à escolha (tabela 5) foi visto que dos 51 alunos, $24(47,0 \%)$ gostariam de escolher enfermagem como primeira prioridade, $11(21,6 \%)$ como segunda e nenhum como terceira. Chama atenção o fato de 16 alunos $(31,4 \%)$ não terem relacionado enfermagem em nenhuma das três prioridades, mesmo estando freqüentando regularmente o curso. Qual viria a ser o desempenho desses alunos durante o curso? O desinteresse aparente ou motivos apontados para a decisão final pela enfermagem estariam relacionados com o comportamento e atitudes por eles apresentados? Só estudos que os acompanhassem durante o curso, poderiam trazer respostas a tais indagações. Embora 24 alunos $(47,0 \%)$ apontassem enfermagem como $1^{\text {it }}$ escolha, $31(60,8 \%)$ declararam na questão 17 que pretendem prestar outros 
vestibulares. Apontam como principal razão para esse fato o desejo de: fazer 2 cursos, cursar educação física para satisfação pessoal ou complementação da educação, cursar medicina, letras ou ciências humanas. Um dos alunos justificou sua opção para melhor preparar-se para o relacionamento de ajuda a pessoas.

Nas justificativas das questões pode-se verificar que os alunos que ainda pretendem cursar medicina, informaram que almejam a realização profissional, enquanto que os pretendentes à área de ciências humanas buscam satisfação pessoal ou complementação da educação.

Entre as razões para a escolha da medicina encontra-se: maior autonomia profissional e desejo que sempre tiveram de optar por essa carreira. A dificuldade de acesso na escola médica foi citada em algumas ocasiões como forte impecilho. Como foi visto na tabela 4 sem dúvida alguma a medicina foi a profissão mais procurada. Os 21 $(31,3 \%)$ alunos que prestaram vestibular para o curso de medicina totalizaram $102(69,3 \%)$ tentativas de ingresso no referido curso. Um dos alunos tentou ingressar 20 vezes num periodo de 2 anos e outro 23 vezes, em 5 anos. É preciso lembrar que este número não inclui os diversos alunos que informaram oralmente que não tentaram medicina porque o número de pontos a ser atingido era muito alto, portanto maior a chance de fracasso.

Ainda na tabela 4 verificou-se que a segunda profissão por ordem de preferência foi enfermagem, num total de 19 alunos $(28,3 \%)$ em 27 tentativas.

As outras profissões preferidas foram odontologia e terapia ocupacional, seguidas por psicologia e fonoaudiologia. Na área de ciências exatas houve duas tentativas para engenharia e duas para matemática. Uma das alunas, a que é casada, é graduada em matemática e exerce a profissão.

Correlacionando informações a partir do mapa geral dos dados, impossivel de ser apresentado em anexo, constatou-se também que nos exames vestibulares de $1981,31(60,8 \%)$ entraram em 2 escolas, além da EEUSP, sendo que $15(29,4 \%)$ deles em duas outras escolas de enfermagem e $16(31,4 \%)$ em uma escola de enfermagem e outras escolas, a saber: $4(7,8 \%)$ em administração de empresas, $3(5,9 \%)$ em serviço social, $3(5,9 \%)$ em psicologia, $2(3,9 \%)$ em odontologia, um $(2,0 \%)$ em farmácia, um $(2,0 \%)$ em prótese e um $(2,0 \%)$ em fonoaudiologia. Com referência à medicina, 1 aluno informou ter sido aprovado em 3 escolas simultâneamente e outros 2 alunos ficaram em listas de espera. Quanto às razões apresentadas para a decisão final pelo curso de enfermagem da EEUSP, a maioria apresentou como razão da escolha final o fato de a escola fazer parte da Universidade de São Paulo.

MORRIS \& RUSSO 5 , preocupados com o grande número de desistência no curso de enfermagem, estudaram os motivos considerados como prioritários pelos alunos para a opção pelo curso. $O$ instrumento de 
pesquisa dos autores foi elaborado a partir de entrevistas com profissionais de enfermagem. Assim, foram relacionados dez itens abrangendo tanto aspectos humanísticos ou altruísticos na escolha da profissão como aspectos matariais. Foram os seguintes os motivos selecionados pelos autores, em ordem de prioridade: ajudar pessoas, interesse pelas ciências e por medicina, excitação e desafio, melhoria da assistência à saúde e desejo de maior relacionamento com as pessoas, recompensa financeira, "status" profissional, segurança, desejo de encontrar pessoas e a presença de enfermeiras na família, influenciando a decisão. Estes mesmos alunos, entretanto, quando solicitados para que apontassem as supostas razões pelas quais outras pessoas teriam escolhido a enfermagem, citaram outros motivos consistentemente diferentes das suas próprias razões. Os quatro motivos principais para as outras pessoas no estudo de MORRIS \& RUSSO ", seriam: ajudar as pessoas, interesse pelas ciências e medicina, recompensa financeira e "status" profissional. Como se pode observar, embora admitindo o interesse pelas ciências biológicas e 0 desejo de ajudar pessoas como objetivos comuns para si e para outros, os alunos, no referido trabalho, demonstraram certa tendência a atribuir razões financeiras e de "status" como fatores de influência mais importantes para seus colegas, reservando para si os motivos mais altruísticos.

No presente trabalho foram elaborados onze itens com base no trabalho de MORRIS \& RUSSO ", adaptados à realidade do meio e segundo a vivência dos autores (tabela 6). Foram considerados pelos alunos, em ordem de importância: interesse pelas ciências biológicas, desejo de ajudar pessoas, preocupação com o nivel de saúde da população, desenvolvimento da personalidade com o objetivo de compreender melhor as pessoas, incentivo da família, interesse financeiro, experiência de trabalho hospitalar ou comunitário, experiências anteriores de hospitalização, ingresso mais fácil na área das ciências biológicas, "status" profissional e presença de enfermeiras na familia.

Esta classificação não surpreendeu as autoras, uma vez que alguns fatos são conhecidos, como o interesse geral pelas ciências biológicas. Também é muito comum os alunos interessarem-se pelos problemas de saúde pública, em geral, o que justifica a preocupação com o nível de saúde da população em $3^{\circ}$ lugar. Repetindo o questionário na turma ingressante em 1982, no $1^{\prime \prime}$ semestre, os três primeiros fatores influenciantes coincidiram com a turma de 1981 . E preciso lembrar, entretanto, que no 1" semestre é oferecida a disciplina Saúde da Comunidade, não se podendo descartar a hipótese de a mesma exercer influência nos alunos quanto à preocupação com o nível de saúde da população. A turma de 1981 já havia cursado esta disciplina e a de 1982 havia cursado mais de $50 \%$ das aulas, quando responderam o questionário.

$E$ evidente que um fator influenciante como "experiências com hospitalização anteriores" não possa ser numericamente representativo, ficando em $8^{\circ}$ lugar, mas sabe-se que ele foi decisivo para 2 alunos 
que haviam sido hospitalizados. Na turma de 1982 também 2 alunos o apontaram como fator decisivo.

O que não se esperava, realmente, é que "ingresso nas ciências biológicas" ficasse em 9" lugar. No grupo de reconhecimento social feito no início do curso, muitos alunos informaram que optaram pela enfermagem porque o número de pontos a ser obtido no vestibular era atingível enquanto que para medicina e odontologia, consideravam-no inatingivel. $E$ possivel que alguns alunos tenham interpretado como sendo difícil o ingresso em qualquer unidade da USP, na área de ciências biológicas, e por esta razão atribuíssem nota mais baixa para este fator. Testando esta questão após a aplicação do questionário, pode-se concluir que foi interpretada diferentemente de uma pessoa para outra.

Não causou surpresa o fato de "interesse financeiro" não estar entre as primeiras razōes, pois sabe-se que não se trata de uma profissão rentável. Evidentemente, uma resposta contrária seria incoerente com a posição dos alunos na questão $\mathrm{n}^{\circ} 20$, (ver Anexo) onde 8 alunos $(15,0 \%)$ julgaram que a enfermeira recém-formada ganha menos de 30 mil cruzeiros (2 salários-mínimos e meio) e 24 alunos $(47,0 \%)$ indicaram entre 30 e 50 mil cruzeiros.

\section{CONSIDERAÇÕES FINAIS}

A vantagem maior foi o conhecimento mais abrangente que as autoras tiveram dos alunos, muitas vezes necessário e utilizado durante a disciplina Fundamentos de Enfermagem.

Novos trabalhos que incluíssem o estudo de outras variáveis poderiam ajudar a direcionar não apenas a tecnologia educacional a ser adotada, tão recomendada por $\mathrm{LOBO}^{3}$ e outros autores, como também auxiliar os docentes no difícil papel de educador. Não se deve esquecer que o estudante deve ser visualizado como um ser em formação, necessitando de acompanhamento que propicie o seu desenvolvimento global como pessoa, e não um ser transformado em mero receptor de informações, muitas vezes oriundos apenas das crenças e valores do docente.

\section{CONCLUSÕES}

A aplicação de um instrumento que procurou caracterizar 51 alunos ingressantes na EEUSP em 1981 indicam que:

1 - 98,0\% são do sexo feminino, na faixa etária de 18 a 22 anos, dos quais $78,4 \%$ de 18 a 20 anos. Procedem em sua grande parte $(70,5 \%)$ da Capital e Grande São Paulo; $96,1 \%$ são economicamente dependente dos pais, mesmo quando exercem atividades remuneradas. A renda familiar de $25,5 \%$ das familias atinge no máximo 5 salários-mínimos e a maioria das famílias $(78,4 \%)$ possue de dois a quatro filhos.

2 - Dos 51 alunos, $24(47,0 \%)$ apontaram a enfermagem como a $1^{\text {: }}$ opção profissional, embora 18 destes já houvessem prestado vesti- 
bulares anteriormente e só 10 tentado enfermagem. A profissão mais procurada pelos alunos antes de 1981 foi a medicina, onde $21(31,3 \%)$ alunos haviam totalizado $102(69,3 \%)$ tentativas, seguida de enfermagem com 27 tentativas: odontologia, terapia ocupacional, psicologia e fonoaudiologia foram as outras profissōes mais tentadas anteriormente. Um aluno tentou medicina 20 vezes e outro 23 vezes, num periodo de 4 a 5 anos.

3 - 60,8\% (31 alunos) declararam que pretendem prestar novos vestibulares. Entre as razōes apontadas destacam-se: desejo de fazer outro curso para complementar a educação; cursar educação física para satisfação pessoal; letras ou ciências humanas e medicina como opção profissional. As razões finais que levaram os alunos a decidirem-se pela EEUSP, mesmo tendo sido aprovados em outras escolas, foram a gratuidade do ensino e por esta ser uma unidade da USP.

4 - Os fatores que influenciaram os alunos na escolha da profissão, foram, pela freqüência decrescente das respostas:

- interesse pelas ciências biológicas;

— desejo de ajudar pessoas;

- preocupação com o nivel de saúde da população;

- desenvolvimento da personalidade com o objetivo de compreender melhor as pessoas;

- incentivo da família;

— interesse financeiro;

- experiência de trabalho hospitalar ou comunitário;

- experiências anteriores com hospitalização;

- ingresso mais fácil na área das ciências biológicas;

- "status" profissional;

- enfermeiras na família.

ARCURI, E. A. M.; ARAÚJO, T. L. de; OLIVEIRA, M. A. C. Factors influencing the freshmen in their professional choice of the "Escola de Enfermagem da Universidade de São Paulo": a research work. Rev. Esc. Enf. USP, São Paulo, 17(1): 5-19, 1983.

The main objective of this study was to find out a some characteristics of the freshman of the Escola de Enfermagem da Universidade de São Paulo, in 1981, and verify which were the reasons that influenced their choice of nursing as a profession. Out of the 80 entering students, 51 answered the questionnaire; $47.0 \%$ indicated nursing as their first options; $60.8 \%$ of them had, in previous years, tried other schools. The answers more often given by these students for their choice of nursing as profession were related ta: interest in biological science, willing to help people and worry with level of well-being of the population. 


\section{REFERENCIAS BIBLIOGRAFICAS}

1. ARCURI, E. A. M. Conheça um pouco de sua opcåo: enfermagem. Rev. Esc. Ent. USP, Săo Paulo, 16(2):127-36, ago. 1982.

2. BARBOSA, E. C. Currículo centrado no aluno, uma abordagem desenvolvimentista. Ed. Bras., Brasilia, 2(4):129-51, 1980.

3. LOBO, L. C. G. O uso de nova tecnologia educacional na formação de recursos humanos. In: SEMINARIO DE DIDATICA APLICADA AO ENSINO SUPERIOR, RIo de Janeiro, 17-21, fev. 1975.

4. MANZOLLT, M. C. \& MONJELEONE, Z. Caracterização do estudante de enfermagem. Ent. Novas Dimens., São Paulo, 3(4):206-14, jul./ago., 1977.

5. MORRIS, P. B. \& RUSSO N. B. Motives of beginning students for choosing nursing school. J. Nurs. Ed., Thorofare, 18(5):34-40, May, 1979.

6. NAKAMAE, D. D. Perfil do estudante de enfermagem. São Paulo, 1976. 68 p. (Dissertação de Mestrado - Escola de Enfermagem USH). 


\section{QUESTIONARIO}

1. Idade $($ )

Estado Civil ( )

Sexo ( )

2. Procedência ( )

3. Residência (tipo)
a) casa dos pais ( )
b) república ( )
c) casa do estudante ( )
d) outros ( ) especifique:

4. Dependência econômica
a) pais ( )
b) bolsa de estudo ( )
c) trabalho ( )

5. Escolaridade dos pais:
a) pai:
b) mãe:

6. Renda familiar:
a) até 3 salários-mínimos ( )
b) até 5 salários-mínimos ( )
c) até 8 salários-mínimos ( )
d) até 10 salários-mínimos ( )
e) até 20 salários-mínimos ( )
f) acima de 20 salários-mínimos ( )

7. Constelação familiar (indique com um $\mathrm{X}$ o círculo correspondente aos membros que compõem sua família, e com asterístico assinale a sua posição)
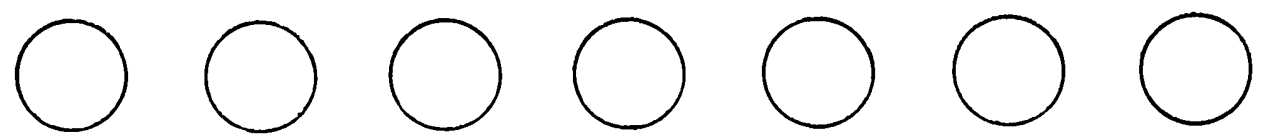

8. Trabalha atualmente?
a) $\operatorname{sim}(\quad)$
b) não ( )

Tipo de trabalho 
9. Desenvolve atividades paralelas ao curso?
a) $\operatorname{sim}(\quad)$
b) não ( )

Tipo de atividade

10. Ao final do $2^{\circ}$ grau, você estava segura(o) para fazer uma opção profissional?
a) $\operatorname{sim}(\quad)$
b) não ( )

Justifique sua resposta:

11. Qual a aceitação de sua família quanto à sua opção profissional?
a) aceitação ( )
b) rejeição ( )
c) indiferença ( )

12. Que expcriências anteriores você teve em exames vestibulares (cite a profissão e o número de tentativas)
a) $\ldots \ldots \ldots(\quad)$
b) $\ldots \ldots \ldots(\quad)$
c) $\ldots \ldots \ldots($ )

13. Cite as nrofissões que você gostaria de escolher em $1^{\text {a }}, 2^{a}$, e $3^{\text {a }}$ opção.

3

14. Em 1981, além de tentar o vestibular na EEUSP, você fez outros exames vestibulares?
a) $\operatorname{sim}(\quad)$
b) não ( )

Em caso afirmativo, indique o nome da entidade e a área ......

15. Foi aprovado(a) em alguma delas?

a) $\sin (\quad)$

b) não ( )

Em caso afirmativo, indique o nome da entidade e a área 
16. Caso tenha respondido afirmativamente a pergunta anterior, o que $o$ (a) levou a optar pela enfermagem?

17. Mesmo já estando na faculdade pretende prestar outros vestibulares?
a) $\operatorname{sim}(\quad)$
b) não ( )

Em caso afirmativo, indique a área

18. Caso tenha respondido afirmativamente a pergunta anterior, aponte os fatores que determinaram a mudança na sua escolha

19. Indique os itens abaixo que determinaram sua escolha da enfermagem. Orientação: atribua a cada item notas de zero $(0)$ a três (3) considerando:

0 - este motivo não lhe ocorreu por ocasião da opção

1 - este motivo não o influenciou na decisão

2 - este motivo influenciou sua decisão

3 - este motivo influenciou fortemente sua decisão (ou foi decisivo para sua decisão)

a) - Interesse pelas ciências biológicas ( )

b) - Ingresso mais fácil na área de ciências biológicas ( )

c) - Preocupação com o nivel de saúde da população ( )

d) - Interesse financeiro ( )

e) - Desejo de ajudar pessoas ( )

f) - "Status" profissional ( )

g) - Enfermeiras na família ( )

h) - Experiências anteriores em hospitais como paciente (pessoal ou familiar ( )

i) - Experiência de trabalho hospitalar ou comunitário ( )

j) - Desenvolvimento da personalidade com objetivo de compreender melhor as pessoas ( )

1) - Incentivo da família ( )

m) - Outros motivos não relacionados (cite os motivos e atribua-lhes a nota correspondente)

20. Na sua opinião qual o atual salário de uma enfermeira recém-formada? 